\title{
Instruções para submissão de trabalhos
}

A revista Novos Cadernos NAEA é multidisciplinar, com periodicidade semestral, dedicada à publicação de trabalhos inéditos, nas seções de artigos originais, artigos de revisão, resenhas, notas científicas, conferências e divulgação de eventos. Eventualmente, algum trabalho pode ser reedição que pela sua relevância, possa merecer maior divulgação. $\mathrm{O}$ objetivo é fomentar o debate sobre enfoques teóricos e resultados de pesquisa, temática ou metodologicamente relacionados à temas sociais e econômicos, culturais e politicos sobre desenvolvimento e meio ambiente, não exclusivamente referidos à região Amazônica na sua dimensaoo continental. A revista adota o processo de avaliação anônima por pares (peer review) e os trabalhos podem ser publicados nos idiomas português, espanhol, inglês e francês.

O processo editorial dos trabalhos submetidos à Revista Novos Cadernos NAEA é iniciado a partir do recebimento dos originais pelo editor responsável. Ao final, são registradas as datas de recebimento e de aprovação dos trabalhos.

Os direitos autorais pertencem ao autor, com direito de primeira edição para a revista Novos Cadernos do NAEA. Em contrapartida, os autores recebem exemplares da revista. A revista é disponibilizada nas versões impressa e on line e os trabalhos são de acesso aberto (open access) e uso gratuito, em aplicações educacionais, científicas e não comerciais. O conteúdo dos trabalhos é de inteira responsabilidade dos autores, não refletindo obrigatoriamente a opinião dos membros do Conselho Editorial da revista.

\section{Artigos originais}

Trabalhos inéditos e relevantes que apresentam resultados de pesquisas e estudos observacionais, experimentais, empíricos e teóricos. Os textos devem conter objetivo, metodologia, resultados, discussão, conclusão, referências e outros elementos estruturais, conforme as normas de submissão de Revista.

\section{Artigo de revisão}

Trabalhos inéditos com base na análise crítica da literatura científica sobre um determinado tema ou área do conhecimento. Os textos devem conter introdução, discussão, conclusão e referências, podendo ser estruturados em tópicos e segundo as normas de submissão da Revista.

\section{Resenha}

Apresenta a síntese e análise crítica sobre o mérito de uma publicação científica ou literária, em que a obra é analisada com base na relevância do seu conteúdo. Deve conter a identificação da obra, cabendo um breve comentário sobre o(s) autor(es) da obra, análise e impressões do autor da resenha, podendo ser estruturada em tópicos.

\section{Nota de Pesquisa}

Apresenta informações sobre uma pesquisa em andamento. O texto deve conter objetivo, hipótese, metodologia e fontes, podendo citar os dados obtidos, progressos, entraves e outros elementos a critério do autor. 


\section{Conferências/Entrevistas}

Publicação de conferências ministradas ou entrevistas dadas por autores de renome nacional e internacional.

\section{Diretrizes para autores}

Os trabalhos submetidos para publicação devem ser originais e inéditos, não sendo permitida a submissão simultânea a outro periódico.

O conteúdo dos trabalhos é de inteira responsabilidade dos autores, não refletindo obrigatoriamente a opinião do Conselho Editorial da Revista Novos Cadernos NAEA.

A revista adota o processo de avaliação anônima por pares (peer review), com base nos critérios de qualidade e rigor científicos, validade dos dados e relevância para a respectiva área de pesquisa.

A aprovação dos trabalhos é condicionada aos pareceres de dois consultores ad hoc (referees) e, em última instância, do Conselho Editorial. Os autores devem acatar as recomendações dos avaliadores, não sendo permitidos acréscimos ou modificações após a aprovação e composição dos trabalhos.

A submissão de trabalhos ao Conselho Editorial da Revista Novos Cadernos NAEA deve ser encaminhada ao editor científico, para o endereço eletrônico da revista: http://www. periodicos.ufpa.br/index.php/ncn.

Os direitos autorais são automaticamente cedidos para a Revista Novos Cadernos NAEA. Em contrapartida, os autores recebem dois exemplares da versão impressa. A revista também é disponibilizada na versão on line, em acesso aberto (open access) e uso gratuito direcionado a fins educacionais, científicas e não comerciais.

\section{Normas para submissão:}

Os trabalhos devem ser encaminhados ao editor científico da Revista Novos Cadernos NAEA, para o site: http:/ /www.naea-ufpa.org/revistaNCN/ojs

\section{Estrutura e formato dos trabalhos:}

Os trabalhos devem ter até 20 laudas, no formato A4, nas fontes Times New Roman ou Arial, corpo 12, entrelinha 1,5, incluindo-se figuras, tabelas e referências.

Os trabalhos devem conter:

Autoria: nome e sobrenome do(s) autor(es) conforme CV Lattes, caso o possua; a mais recente titulação acadêmica; filiação institucional; cargo que ocupa; área de atuação; e-mail e endereço completo para correspondência.

Título: deve ser direto e conciso, no idioma original do texto, acompanhado de tradução para o inglês.

Resumo: parágrafo único, no idioma do texto, com 150 palavras no máximo, contendo uma síntese que sinalize para objetivos, metodologia, discussão e conclusões.

Abstract: tradução do resumo para o inglês caso o texto não seja neste idioma.

Palavras-chave: de quatro (mínimo) a seis palavras (máximo) que identifiquem o conteúdo 
do trabalho.

Keyowrds: tradução das palavras-chave, para o inglês caso o texto não seja neste idioma.

Figuras (fotos, mapas, gráficos etc.): são impressas em preto e branco (tons de cinza), compatíveis ao formato da revista (não excedendo $15 \times 21 \mathrm{~cm}$ ). Para garantir a qualidade editorial das figuras, elas devem ser enviadas em arquivos separados, em JPEG ou TIF, com resolução mínima de 300 dpi. Devem ser obrigatoriamente citadas no corpo do texto, seguindo a ordem sequencial de inserção, numeradas em arábicos, com créditos de autoria e fontes nas respectivas legendas.

Tabelas: devem ser produzidas e inseridas no texto nos softwares Word ou Excel, obedecendo o formato da revista (não exceder $12 \times 20 \mathrm{~cm}$ ). Devem obrigatoriamente citadas no texto, seguindo a numeração sequencial de inserção.

Citações bibliográficas: as referências devem ser obrigatoriamente citadas no corpo do texto: sobrenome do autor e ano (em maiúsculas quando estiverem entre parênteses).

Citações de texto: até três linhas, devem ser entre aspas, seguindo o formato do texto, com citação de autoria no final, entre parênteses. As citações longas (quatro linhas ou mais) devem ser em parágrafo separado, com recuo de $4 \mathrm{~cm}$, entrelinha simples, corpo 10, com citação de autoria no final, entre parênteses.

Nota de rodapé (opcional): devem ser inseridas no caso de comentários e informações complementares ao texto, seguindo a numeração sequencial, corpo 10.

Referências: A revista adota a Normalização de Referências Bibliográficas da ABNT (NBR 6023/2002). Todas as referências citadas no texto devem constar no tópico final, em ordem alfabética.

\section{Exemplos:}

- Artigos em periódicos:

SOBRENOME, Prenome abreviado. Título: subtítulo (se houver). Nome do periódico (em negrito), Local de publicação (opcional), volume, número ou fascículo, paginação, ano.

GORENDER, J. A sociedade cindida. Estudos Avançados, v.28, n.80, p.17-26. 2014.

\section{- Capítulo de livro e coletânea:}

SOBRENOME, Prenome abreviado do autor do capítulo. Título: subtítulo (se houver). In: SOBRENOME, Prenome abreviado do(s) Org.(s.), Ed.(s.). Título do livro: subtítulo do livro (se houver). Local de publicação: Editora, ano. Paginação do capítulo.

LEIS, H. R. Especificidades e desafios da interdisciplinaridade nas ciências humanas. In: PHILIPPI JUNIOR, A.; SILVA NETO, A. (Eds.). Interdisciplinaridade em Ciência, 
Tecnologia \& Informação. Barueri: Manole, 2011. p. 106-122.

- Livro no todo:

SOBRENOME, Prenome abreviado. Título: subtítulo (se houver). Edição (se houver). Local: Editora, ano. Paginação/volume. (Coleção ou série, se houver)

SAID, E. Orientalismo: o Oriente como invenção do Ocidente. Tradução de Rosaura Eichenberg. São Paulo: Cia. das Letras, 2007. 528p.

\section{- Dissertações e teses:}

SOBRENOME, Prenome abreviado. Título: subtítulo (se houver). Ano de defesa. Total de folhas. Tese (Doutorado em...) ou Dissertação (Mestrado em...) - instituição, local, ano.

COSTA, F. S. A dinâmica dos recursos comuns em Unidades de Conservação e Assentamentos Rurais no Amazonas: uma abordagem fuzzy set. 2014. 365f. Tese (Doutorado em Ciências Socioambientais) - Núcleo de Altos Estudos Amazônicos, da Universidade Federal do Pará, Belém, 2014.

\section{- Documentos em meio eletrônico}

SOBRENOME, Prenome(s) abreviado(s) ou INSTITUIÇÃO. Título: subtítulo (se houver). local de publicação, volume (se houver), ano. Disponível em: <endereço da URL>. Acesso em: dia, mês (abreviado), ano.

OBSERVATÓRIO DAS METRÓPOLES. As metrópoles no Censo 2010: novas tendências? Disponível em: <http://www.observatoriodasmetropoles.net>.Acesso em: 2 fev. 2011.

\section{Política de Privacidade}

Os nomes e endereços informados nesta revista serão usados exclusivamente para os serviços prestados por esta publicação, não sendo disponibilizados para outras finalidades ou a terceiros.

\section{Endereço}

Site: http:/www.naea-ufpa.org/revistaNCN/ojs

E-mail: revistancnaea@ufpa.br

Universidade Federal do Pará

Núcleo de Altos Estudos Amazônicos/NAEA - Sala 206

Cidade Universitária Prof. José Silveira Neto -Setor Profissional

Rua Augusto Corrêa, no 01 - Guamá

CEP: 66075-900 Belém-Pará-Brasil

Fones (55-91)3201 8515 